\title{
Prevalence of Iron Deficiency Anaemia in Children Attending ICDS Center in a Tier II City
}

\author{
Dr.A.Umashankar MD (Paed) ${ }^{1}$, Dr.P.Senthilkumar MD.DM ${ }^{2}$. \\ ${ }^{1.2}$ Assistant Professor, Department of Paediatrics Coimbatore Medical College Hospital, Coimbatore
}

\begin{abstract}
:
Introduction: Anemia is known to be a significant global problem affecting 305 million School Aged Children. Prevalance of anemia according to National Family Health Survey (NFHS-3) reveals 70-80\% in children. ${ }^{l}$ And developing countries, prevalence rates of $29.2 \%$ to $79.6 \%$ have been reported, with $13.6 \%$ in South East Asia.

Estimation of prevalence of anemia is helpful only if they are associated with determination of causative factors that contribute to the development of anemia. Though anemia is an important public health problem, there are numerous countries which lack national prevalence data. Most survey includes mainly: preschool age children, non pregnant women of reproductive age and pregnant women . ${ }^{2}$

An increased prevalence rate in school aged children reflects inadequate nutritional iron intake, generalised malnutrition or low iron bioavailability of diet. The consequences of iron deficiency are many and seriously affect not only individuals' health but also development of societies and countries. ${ }^{3,4}$

In order to know the prevalence of iron deficiency anemia among young children, this study included children from 30 ICDS centres.

This study concentrated on the risk factors for anemia in the family and social level, which may help in reducing the prevalence of iron deficiency anemia at the community level \& thus percentage of the morbidities due to iron deficiency in growing children.

Objective: To Determine the prevalence, risk factors and associated common deficiencies of iron deficiency anemia among 2-5 yr children attending ICDS centres and to know the knowledge \& practice by their mothers regarding iron deficiency anemia prevention

Design: cross-sectional observational study.

Setting\& Participants: Total of 732 Children in 30 ICDS Centers around the Peelamedu region in Coimbatore during October 2014 to September 2015.

Method: Detailed history obtained using specific questionnaire in typed format and complete physical examination was done in all. Hematocrit, $M C V, M C H, R D W$, peripheral smear and reticulocyte count done in all children whereas S.Ferritin, TIBC done for confirmation of iron deficiency anemia within 3 days duration.

Results: Prevalence of anemia among children of ICDS centers of Coimbatore from the present study is $12.15 \%$. From the present study, the prevalence of clinical pallor is found to be 16\%(117) among which $12 \%(89)$ are anemic. Intiation of cow s milk earlier is a important risk factor for development of anemia contributing to $24 \%$ population. Among the group who gives history of passing worms in stools $30 \%$ are in anemic group and 3.6\% are in non anemic group. ODDS Ratio comes around 11.7 and relative risk comes around 8.4 times.

Conclusion: The overall prevalence of anemia in our study was less as compared to other Studies which could be attributed to regular deworming and Iron and Folic acid supplementation by the Health Authorities since 2003 and effective functioning of Mid Day Meal programme. Additionally, a diet rich in Vitamin A should be supplemented.
\end{abstract}

Keywords: Iron deficiency anaemia, ICDS centers, risk factors.

\section{Methodology}

30 ICDS centers around peelamedu region are selected and prior information regarding the visit is informed 2 weeks before. After getting consent from parents, detailed history is obtained using specific questionnaire in typed format and complete physical examination was done in all. Socio-economic status classified based on Modified Kuppusamy scale. Children in 2-5 years age group are clinically examined for signs of iron deficiency anemia and other Vitamin deficiencies. Anthropometry readings are entered. Height was measured by wall mounted fiber glass tape and weight was measured with mechanical weighing scale and BMI was calculated.

BMI was categorized as low when it was less than 14 for 2-3 year age group and less than 15 for 3-5 year age group. Two different Growth charts for Male and Female separately were used. 
Around $3 \mathrm{ml}$ of blood is drawn in EDTA sample tube using disposable syringe from all the children to determine hemoglobin, Hematocrit, MCV, MCH, RDW peripheral smear and reticulocyte count. From those children, who are found to be clinically pale, another $3 \mathrm{ml}$ of blood is drawn and S.Ferritin, TIBC done for confirmation of iron deficiency anemia within 3 days duration.

Hemogobin, MCV, MCH, RDW are determined by using Sysmex KX-21 auto analyzer. S.Ferritin and TIBC are done by Chemiluminisence immune assay. The blood cell counting is based on the impedance principle with both the cell counts and histograms obtained through the analysis of blood cell dilution. It employs three detector blocks and two kinds of reagents for blood analysis. The WBC detector using DC detection method, measures WBC count. The RBC and platelet counts are measured by RBC detector blocks and it also employs the DC detection method. The HGB detector block measures the hemoglobin concentration by using the non-cyanide method. Ideal, tongue shaped peripheral smears were prepared on clean glass slides and stained with Leishman's stain using the following standard procedure. When the slides were dry, they were examined under oil immersion lens. The number of RBCs and the reticulocytes were counted in 10 to 15 fields.

The data was entered in excel data sheet and the chi square test was used assess differences in categoric variables between groups. Comparsion between groups was made by the Non parameteric Wilcoxon Rank test. Odds ratio and Relative Risk were determined. A p value of $<0.05$ using a two-tailed test was taken as being of significance for all statistical tests. All data were analysed with a statistical software package. (SPSS, version 16.0 for windows)

\section{Results}

The present study was undertaken to know the prevalence of anemia in ICDS children and to know the influence of factors like sex, socioeconomic status and diet as a causative factor for anemia.

This is a cross sectional observational study conducted from Oct 2013 to Sep 2014. Total of 732 Children in 30 ICDS Centers around the Peelamedu region in Coimbatore were studied. These children were given Iron and Folic acid supplementation by Ministry of Health and Family Welfare. Children aged 2-5 years received $30 \mathrm{mg}$ elemental iron and $250 \mathrm{mcg}$ folic acid daily for 100 days a year. Biannual deworming was done in all. All children were provided with mid day meal which provided $1 / 3 \mathrm{rd}$ of the total calorie requirement and $1 / 2$ of the total protein requirement.

From the study population of 732, clinical pallor was present in (16\%)117 members of which(12\%) 89 members are anemic (Table:1). From the present study, among the pallor group 31\% (36) are moderately anemic and 45\% (53) of are mild anemic and 24\% (28) have normal hemogliobin. And $100 \%$ ( 615) of NoPallor group have normal hemoglobin. Prevalence of anemia among children of ICDS centers of Coimbatore from the present study is $12.15 \%$. The prevalence of anaemia in our study was almost similar to that in study by Mutthayya et $\mathrm{al}^{5}$. WHO study has included children worldwide where prevalence was $25.4 \%$ (Table: 2 ). In the study by Djokic et $\mathrm{al}^{3}$, most of children studied were non vegetarians. In our study there was improvement in prevalence rate i.e. $12.15 \%$, similar to study by S Mutthayya et al. The reason for this low prevalence would be the regular deworming and Iron and Folic acid supplementation by the School Authorities since 2003. In combination with these interventions, the consumption of a simple rice-based lunch supplying roughly 300-400 $\mathrm{kcal} /$ day may not only improve the overall nutritional status of school aged children, but also contribute a small amount of iron each day. 6,7

$43 \%$ of male (38/89) are found be anemic and $57 \%$ of females (51/89) are found be anemic. Anemia is equally distributed in male and female children. There was no significant difference between prevalence of anemia in males and females in our study which can be attributed to the improvement in nutritional status of females because of provision of meal at school without any partiality.

Of the total population of lower SES 29\% (26/89) are in anemic group and 2.1\% (13/643) Non-anemic group and in upper lower SES 58\% (51/89) are in anemic Group and $10.4(67 / 643) \%$ are Non-anemic group and in lower middle SES 14\% (12/89) are anemic group and 87.5\% (563/643) are Non-anemic group. So anemia occupies a large population of lower SES ${ }^{9}$. In both the studies, prevalence of anaemia was more in upper lower (class IV) SES as the total number of children in upper lower SES in our study was more.

Among the population, who initiates cow's milk earlier before 6 months of age $73 \%(65)$ are in pallor group and $6 \%$ (39) are no-pallor group. So intiation of cow's milk earlier is a important risk factor for development of anemia contributing to $24 \%$ population ${ }^{8}$. Of the population who consumes non-veg monthly once $33 \%(31)$ are among anemic group and 2.5\%(16) are Non- anemic group and among those who consume Bi-weekly $48 \%$ (43)are among anemic group and 9.3\% (60)are in Non anemic group and in those who consume weekly $17 \%(15)$ are in anemic group and $88.2 \%(567)$ are in Non anemic group. So population who are on monthly/biweekly non veg diet are more affected by anemia than those with who take weekly. 
Among the group who gives history of passing worms in stools $30 \%$ are in anemic group and $3.6 \%$ are in non anemic group and among those who have no such history $70 \%$ are in anemic group and $96.4 \%$ are in Non- anemic group with $\mathrm{P}$ value of $<0.01$. ODDS Ratio comes around 11.7 and relative risk comes around 8.4 times. So, worm infestations leading to anemia, is proved stastically significant.

Among the population who do not take regular ICDS food $75 \%$ are in anemic group and $7.5 \%$ are in nonanemic group. And among those who take regulary $25 \%$ are in anemic group and $92.5 \%$ are in anemic group. So, regular intake of ICDS food has a role in prevention of anemia, which is found to be statistically significant.

Among the population who have low BMI $43 \%$ are in anemic group whereas non anemic group have normal BMI and relative risk comes around 14.7. It was found that prevalence of anemia was more in children with low BMI and was similar to study by Djokic et $\mathrm{al}^{3}$. This shows that anemia is influenced by nutritional status of the children. Among the pallor group $62 \%(72)$ are $1^{\text {st }}$ order $32 \%(38)$ are $2^{\text {nd }}$ order $6 \%(7)$ are $3^{\text {rd }}$ order birth. Among the No-pallor group $70 \%(433)$ are $1^{\text {st }}$ order $26 \%(162)$ are $2^{\text {nd }}$ order $3 \%(20)$ are $3^{\text {rd }}$ order birth with $\mathrm{P}$ value of $>0.05$. So, the relation of birth order with anemia is statistically insignificant.

Majority of anemic children were admitted for several illness like Febrile seizure, respiratory tract infections when compared to $5.5 \%$ non anemic

children requiring hospital admissions. Eye signs [Conjunctival Xerosis (35/89)/ Bitot Spots (12/89)] are more common manifestation among children with iron Deficiency anemia, suggestive of vitamin A deficiency. Prevalence of Iron Deficiency as found by Serum Ferritin $<15 \mathrm{mcg} / \mathrm{L}$ and TIBC was found to be $16 \%$. Iron deficiency anemia as indicated by the low Serum ferritin level was seen in all 85 children with anemia. However Serum Ferritin ${ }^{10}$ was low in total of 113 children, which indicated that 28 children were in Iron Deficiency State without manifesting anemia. Out of this, Iron deficiency anemia was in $12.15 \%$ with the rest i.e. $3.85 \%$ being in Iron deficiency state. $40 \%$ of mothers of anemic children have poor knowledge about iron rich diets $11 /$ IDA and only $30 \%$ practice iron rich diet out of $60 \%$ those who have good knowledge, as against to $90 \%$ practice by $89 \%$ knowledged mother ${ }^{12}$ belong up the non- anemic group.

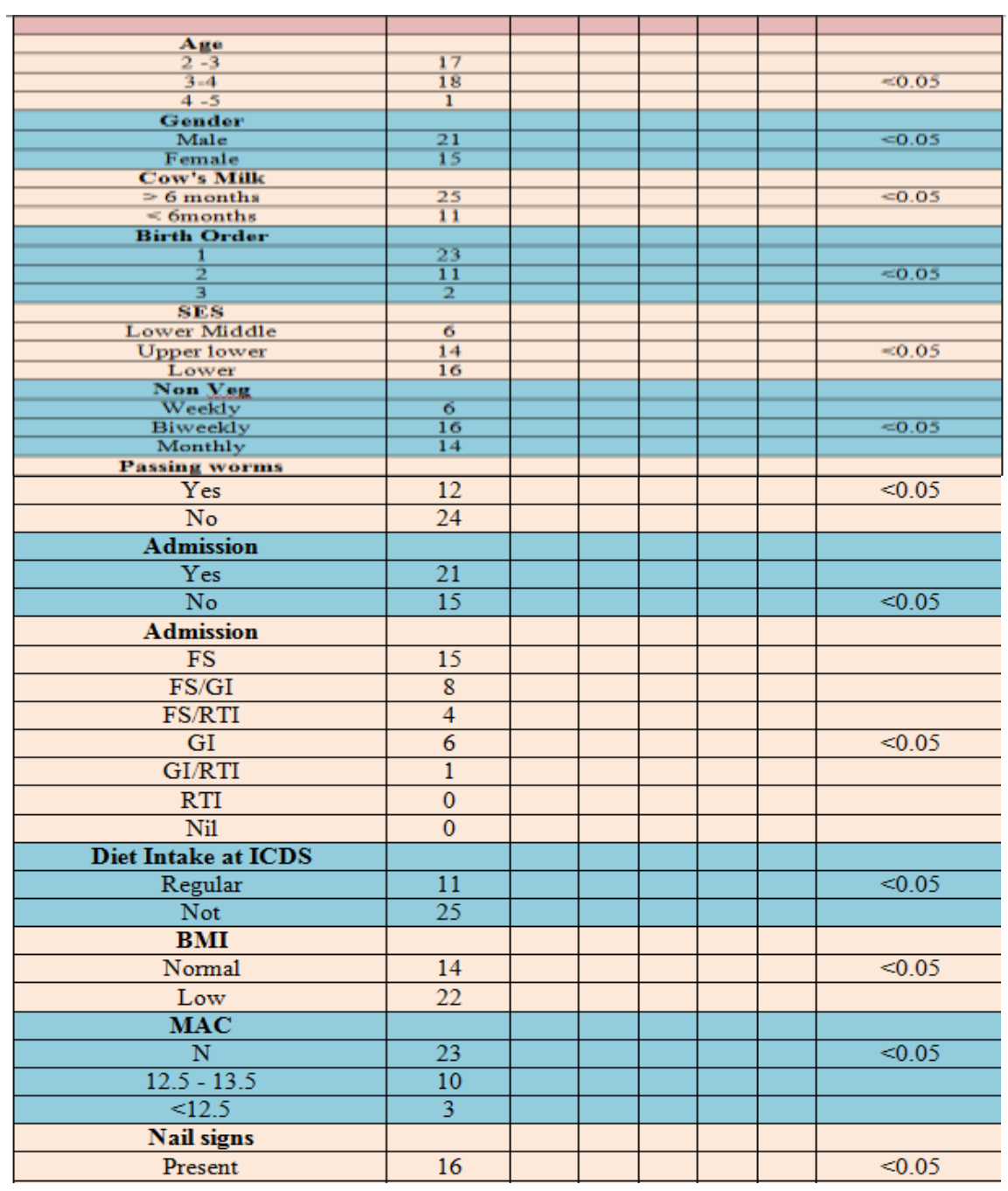




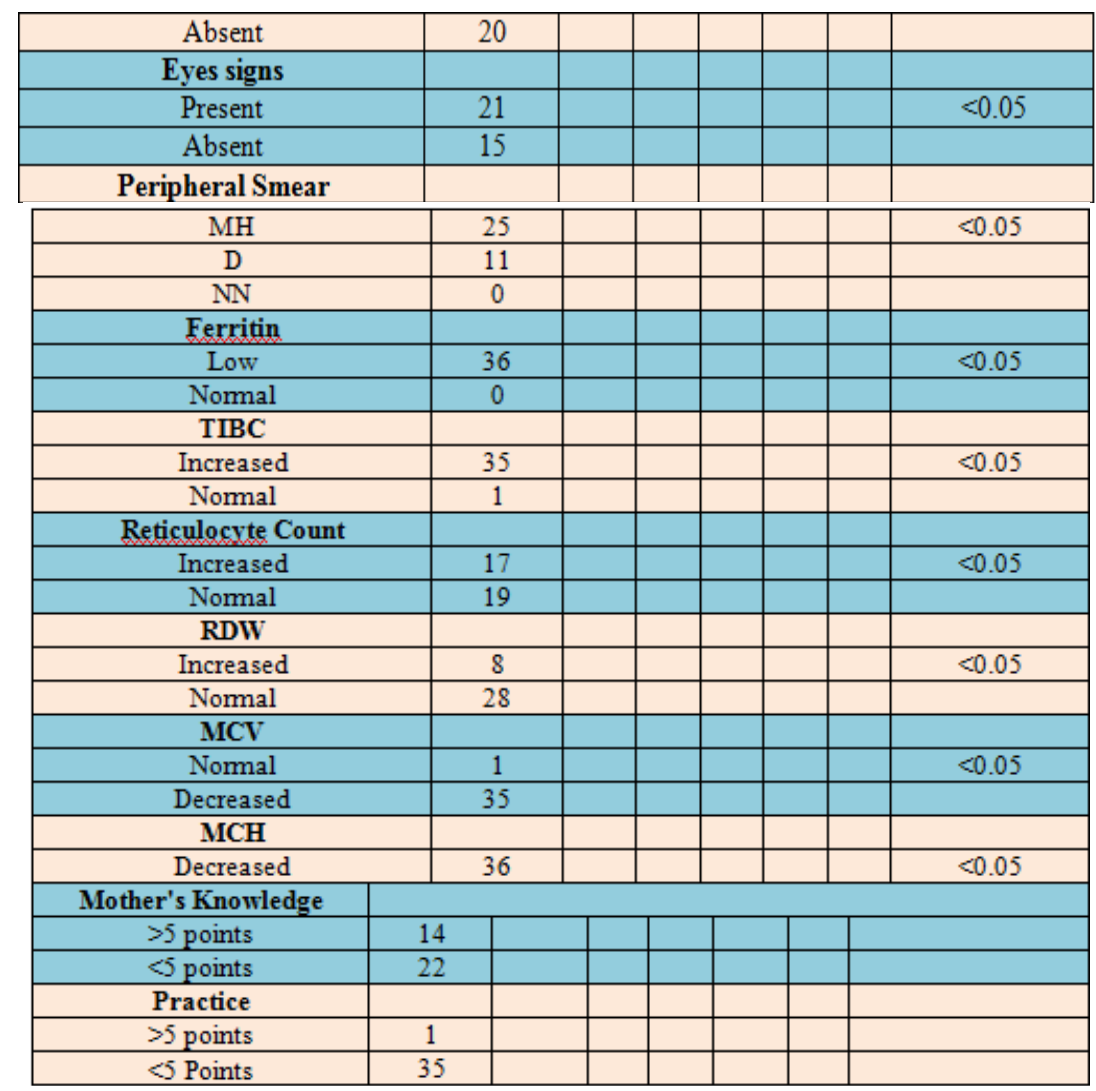

Table :1 Assessment of $\mathrm{HB}$ with other clinical variables.

The overall prevalence of anemia in our study was less as compared to other Studies however; iron deficiency state was significantly present as detected by Low serum ferritin. Major factors which influence the prevalence of anemia was nutrition and Socioeconomic status, introduction of cow's milk before 6 months of age and worm infestation along with varying knowledge and practice by mothers.

Table :2 comparison with other studies

\begin{tabular}{|l|c|c|c|c|}
\hline \multicolumn{1}{|c|}{ Studies } & $\begin{array}{c}\text { WHO World } \\
\text { wide study }\end{array}$ & Djokic D & S Mutthayya & Present Study \\
\hline $\begin{array}{c}\text { Prevalence } \\
\text { of Anaemia }\end{array}$ & $25.4 \%$ & $18 \%$ & $13.6 \%$ & $\mathbf{1 2 . 1 5 \%}$ \\
\hline Male & - & $73 \%$ & $44.9 \%$ & $\mathbf{4 3 \%}$ \\
\hline Female & - & $27 \%$ & $55.1 \%$ & $\mathbf{5 7 \%}$ \\
\hline BMI low & - & $72 \%$ & - & $\mathbf{5 1 \%}$ \\
\hline Normal BMI & - & $18 \%$ & - & $\mathbf{4 1 \%}$ \\
\hline
\end{tabular}

\section{Key Messages}

- The overall prevalence of anemia in our study was less as compared to other Studies however; iron deficiency state was significantly present as detected by Low serum ferritin.

- Major factors which influence the prevalence of anemia was nutrition and Socioeconomic status, introduction of cow's milk before 6 months of age and worm infestation along with varying knowledge and practice by mothers.

- The overall improvement in prevalence of anemia in ICDS children could be attributed to regular deworming and Iron and Folic acid supplementation by the Health Authorities since 2003 and effective functioning of Mid Day Meal programme. Additionally diet rich in Vitamin A should be supplemented. 


\section{References}

[1]. Addressing iron deficiency anaemia: 12 by 12 initiative. /en/ Section6 / Section324_1467.htm

[2]. Benoist B, McLean E, Cogswell M, Egli I, Wojdyla D. World-wide prevalence of anemia 1993-2005. WHO Global Database on Anemia. Geneva: World Health Organization; 2008.

[3]. Djokic D, Drakulovic MB, Radojicic Z, Crncevic Radovic L, et al. Risk factors associated with anemia among Serbian schoolage children 7-14 years old: Results of the first national health survey. Hippokratia 2010;14:252-60.

[4]. Norma B. Lerner, Nelson textbook of Pediatrics: 16th edition: Saunders;2011: 1648- 1649.

[5]. S Mutthayya, P Thankachan, M B Zimmermann, M Andersson, et al. Low anemia Prevalence in school-aged children in Bangalore, South India: Possible effect of School Health initiaives. E J Clin Nutr 2007, 61,865-869.69

[6]. Rachana Bhoite, Uma Iyer. Magnitude of Malnutrition and Iron Deficiency Anemia among Rural School Children: An Appraisal ASIAN J. EXP. BIOL. SCI. VOL 2(2) 2011]

[7]. B. Sudha Gandhi, Sivapatnam Sundaresan, W.Ebenezer William, A. Prema. Prevalence of anemia in the school children of Kattankulathur, Tamil Nadu, India, www. ijnpnd.com/article. asp?issn=223 1-0738;year=2011.

[8]. Jain S. Anemia in children: Early Iron Supplementation. Indian J Pediatrics 2000; 67(1): 19-21.

[9]. Sahana KS, Ghaliyah K, Anitha P, Prakash S. A Study of Anemia in Hospitalised Infants at a Tertiary care Hospital. Ntl J of Community Med 2015; 6(2):22-27.

[10]. WHO. Serum ferritin concentrations for the assessment of iron status and iron deficiency in populations. Vitamin and Mineral Nutrition Information System. Geneva, World Health Organization, 2011 (WHO/NMH/NHD/MNM/11.2).

[11]. Infant and child feeding guidelines 2010.infant and child feeding chapter,Indian academy of pediatrics.indian pediatr 2010;47:9941004

[12]. Kambli S. Mother's Knowledge Regarding Weaning Process in Infants. International Journal of Science and Research 2014; 3(7): 1192-1197. 